\title{
THE EFFECT OF METEOROLOGICAL PHENOMENA ON ACUTE MYOCARDIAL INFARCTION IN STAMFORD, CONNECTICUT*
}

\author{
BY \\ D. H. FOGEL AND NORMAN RIGHTHAND \\ From the Department of Medicine, Stamford Hospital, Stamford, Connecticut, U.S.A.
}

\begin{abstract}
About 2500 years ago Hippocrates (Jones, 1948) recognized the importance of the effects of weather and climate on man. Others (Petersen, 1947a; Mills, 1939; Huntington, 1938) have also observed this, stating that weather is principally the reason for certain cyclic variations in sickness and death rates. Chief among these cycles in health are the seasonal variations. In temperate regions, there is decreased illness in summer warmth and a rising tide of ill health through the winter months to a February or March peak.

Besides the influences of seasonal weather, there is an irregularly recurring cycle of change in sickness that appears to be related to sun spot activity (Mills, 1942). There appears to be also a positive relation between sudden changes in weather and the development of various disease states (Fabricant, 1939, 1940; Rentschler, Vanzant, and Rowntree, 1929; Mitchell, 1877; Hayes, 1961 ; Thomas, Holljes, and Eisenberg, 1961). The following study was undertaken to ascertain the effects of weather on a specific disease state; namely, acute myocardial infarction.
\end{abstract}

A review of the published material reveals that various meteorological phenomena appear to affect the incidence of cardiovascular diseases, generally, and acute myocardial infarction, specifically. One of the earliest observations was a statistical analysis in 1925 (Stocks, 1925) which noted a correlation between the number of deaths from cardiovascular diseases and the barometric pressure. In England and Wales (Cowdry, 1933), deaths due to cardiovascular-renal disease were found to reach a maximum in December, January, and February when the mean temperature was lowest, and declined to a minimum in August when the mean temperature was highest. Sudden changes in weather have been observed to accompany the development of acute thromboembolic phenomena and cardiovascular dysfunction (Newton, 1951; De Takats, Mayne, and Petersen, 1940; Halse and Quennet, 1948).

The first reference to any relation between season and acute myocardial infarction was in 1926 (Wolff and White, 1926) when it was observed that "most of the cases of coronary thrombosis in New England occur in winter, and the onset of all 19 cases except one occurred in the months from October to April inclusive". Subsequent reports (Mullins, 1936; Master and Jaffe, 1952; Wood and Hedley, 1935; Bean and Mills, 1938; Mintz and Katz, 1947) from the northern portions of the United States revealed a decreased frequency of occurrence during the summer months and an increased frequency during the winter. However, there are other reports (Smith, Keyes, and Denham, 1951; Jacobs, 1951) from similar areas in the United States that do not reveal any striking seasonal incidence in the occurrence of acute myocardial infarction.

\footnotetext{
* This study was aided by a grant from the Stamford-Darien-New Canaan Heart Association.
} 
In the milder climates of the southern portions of the United States, such as Los Angeles, Houston, and Nashville, there was also (Schnur, 1956; Hoxie, 1940; Billings et al., 1949) an increased frequency of occurrence of acute myocardial infarction in the winter months. In Dallas (Heyer, Teng, and Barris, 1953), where there are very hot summers, the highest incidence occurred in the summer months. In a follow-up report (Teng and Heyer, 1955), these paradoxical findings were attributed to sudden changes in weather; namely, there was an increased frequency of occurrence of acute myocardial infarction during periods of sudden inflow of polar air or tropical air masses, especially the former. Petersen (1947a) was apparently the first to draw attention to the relation of sudden weather changes and the increased incidence of acute myocardial infarction. Deaths showed a close relation to climatic stress (Brown and Pearson, 1948; Bundesen and Falk, 1926). A recent observation in the Soviet Union (Afanasieva, 1957) noted an increased frequency of acute myocardial infarction during the colder months and with sudden weather changes.

No attempt has yet been made to correlate the effects of sun spots and cosmic rays on the incidence of illness. To elucidate these meteorological factors further, a study was made in which mean temperature, barometric pressure, humidity, sun spots, and cosmic rays were correlated with the number of attacks of acute myocardial infarction in Stamford, Connecticut from 1952-1958, inclusive.

\section{METHOD}

The number of attacks of acute myocardial infarction for the years 1952-1958, inclusive, was obtained by reviewing the patient charts of the Stamford and St. Joseph's Hospitals, Stamford, Connecticut. The criteria for acute myocardial infarction conformed to the following (one or any combination thereof): (a) a clinical history of classical chest pain; (b) typical electrocardiographic changes; (c) clinical or laboratory signs of tissue death compatible with infarction, and/or (d) evidence found at post-mortem examination.

Additional data were obtained from the death certificates recorded during the years 1952-1958 in the Town Clerk's office, Stamford, Connecticut. A large majority of these deaths from acute myocardial infarction had a similar previous hospital diagnosis. The total number of deaths from all causes for Stamford, Connecticut, was taken from this source.

A fatal attack of acute myocardial infarction was considered to be one in which death occurred within one month of the onset.

Meteorological Data. The meteorological data were assembled from several sources. For the years 1952-1958, the monthly values of total precipitation and maximum, minimum, and average temperature were obtained from the reports of the U.S. Weather Bureau Station, Stamford, Connecticut. Monthly values for maximum, minimum, and average barometric pressure were taken for the same years from the reports of the U.S. Weather Bureau Station, La Guardia Field, New York. This was the nearest source from which these data were readily available. For the sun spot data, monthly, unsmoothed, relative numbers (Zürich) were used as recorded in the Solar Bulletin of the American Association of Variable Star Observers and in Sky and Telescope. The cosmic ray data were taken as published for Cheltenham, Maryland by the Carnegie Institution, Washington D. C. Some recent values, unpublished at the time of the study, were generously provided by this institution.

The effect of the above meteorological data on the occurrence of attacks of acute myocardial infarction was observed by computing the coefficient of correlation. The procedure was that devised by Dr. C. H. Smiley, Brown University, Providence, R. I., and is known as Correlation By Thirds (1960). This method does not require the relation between two variables to be linear. The coefficient that is found is a better measure of the correlation of two variables. In the common product-moment method of determining a coefficient of correlation, the coefficient may be small because there is no relation between the two variables, or because the relation is not linear. Coefficient By Thirds reports on apparent relations, not final, pointing out the possibilities for further study.

A coefficient of $+0.6,+0.59$ to +0.3 , and +0.29 to +0.25 signifies a high, medium, and low correlation, respectively. Where the coefficient is a minus sign in the above ranges it is a high, medium, and low inverse correlation. A value of $+\mathbf{0 . 2 4}$ or less signifies a very low to no correlation. When a significant correlation was obtained, its statistical significance was evaluated in accordance with the $\chi^{2}$ test, using the 5 per cent critical region (Hoel, 1947). 


\section{Statistical Study}

Incidence of Attacks of Acute Myocardial Infarction. During the years 1952-1958 in Stamford, Connecticut there were 1663 attacks of acute myocardial infarction. The largest number of attacks occurred in the sixth decade (536), with decreasing numbers in the fifth (394) and seventh decades (366), respectively: 78 per cent of all attacks occurred in these three decades; while 11.6 per cent (194) occurred in the second, third, and fourth; and 10.4 per cent (173) in the eighth and ninth decades of life. It was noted that in the fifth and eighth decades, the women had the same number of attacks; whereas, the men had five times as many in the fifth decade as compared to the eighth.

Fatal Attacks of Acute Myocardial Infarction. The overall percentage of fatal attacks in this series was $61 \cdot 5$. Considering the authors' source of material, namely, hospital cases and death certificates, it was expected that the mortality rates would be high since this study concerned the more severe form. Early studies (Gould, 1953) which reported the more severe cases of acute myocardial infarction estimated the mortality to be about 50 per cent.

It has been noted (Friedberg, 1949) that the mortality from acute myocardial infarction was twice as great beyond the age of 60 years as below. This appeared to parallel the fourth and fifth decade in the present study but not the third decade which had a higher mortality than the fourth and fifth.

Attacks of Acute Myocardial Infarction in Men. Of the total number of attacks during the period of study, 1086 attacks occurred in men. The incidence of attacks in men paralleled closely the total incidence (male and female) described above. The percentage of fatal attacks in this group according to decades was: second-0; third-53.9; fourth-42.4; fifth-43.8; sixth-61.9; seventh-71.0; eighth -84.4 ; and ninth -83.4 . The overall mortality of male attacks was 56.9 per cent or 620 fatal attacks of acute myocardial infarction.

Attacks of Acute Myocardial Infarction in Women. There were 577 attacks compared to 1086 attacks in the male. This represents a female to male ratio of 1.0 to 1.9. The greatest number of attacks in women occurred during the sixth decade (190), with decreasing numbers in the seventh (170), eighth (92), and fifth (91), respectively.

The percentage of fatal attacks in women according to decade was: third $-50 \cdot 0$; fourth $-57 \cdot 2$; fifth-54.9; sixth-66.8; seventh-71.2; eighth-89.1; and ninth-90.9. The overall mortality was 69.7 per cent or 402 fatal attacks of acute myocardial infarction. Compared with the men in the present study, the women had the higher overall and decade mortality rates.

Most studies of acute myocardial infarction report that women have a higher mortality rate than men and that they are older (Gould, 1953; Chambers, 1946) at the onset of acute myocardial infarction. These studies recorded the ratio of men to women as 3 to 1 whereas the ratio in the present study was 1.9 to 1 . This is probably a cardinal factor in the higher rate of fatal attacks of acute myocardial infarction in the present series.

Seasonal and Monthly Incidence. During the spring months (March, April, May) 450 attacks occurred; 406 occurred both in the summer (June, July, August) and in the autumn (September, October, November); and 401 occurred in winter (December, January, February). The three highest monthly incidences were April (165), May (157), and January (151). The lowest monthly incidences were August (121) and December (124). The differences in seasonal and monthly incidences are not statistically significant.

A study was made to ascertain what month was more favourable for surviving an attack. January with survival rates of 32.4 and 17.4 per cent for men and women, respectively, appeared to be the least favourable month. August with a survival rate of 52.5 per cent for men and July with a rate of 44.4 per cent for women appeared to be the most favourable months. However, statistical analysis of these prognostic percentages was not significant.

Relation of Attacks to Total Deaths. No direct correlation was observed. The total deaths from all causes were lowest (755) in 1953 and highest (925) in 1957, when all acute myocardial infarctions represented 29.0 and 30.7 per cent, respectively, of these deaths. The percentage of 
fatal attacks in 1953 and 1957 was $68 \cdot 2$ and 50.3, respectively. However, the difference in the latter percentages was not statistically significant.

\section{Correlation of Meteorological Data with Acute Myocardial Infarction}

To ascertain the effect of meteorological phenomena on the incidence, the attacks of acute myocardial infarction were divided into three main categories in this part of the study: Total attacks, men and women; total attacks, men; and total attacks, women. For comparative purposes a fourth category was included; namely total deaths from all causes, except acute myocardial infarction. These four categories were correlated with the monthly averages of meteorological data for the years 1952-1958 by the method, Correlation By Thirds.

No correlation between the incidence of attacks of acute myocardial infarction in the three listed categories was found with temperature, precipitation, barometric pressure, sun spot activity, and cosmic rays. Temperature fluctuations and sudden wide fluctuations of barometric pressure had no significant coefficient of correlation with the incidence of attacks. However, it was noted that increased sun spot activity had a medium coefficient of correlation $(+0.339)$ with the total deaths from all causes, except acute myocardial infarction; that is, it had a moderate augmenting effect on the incidence of deaths from all causes, except myocardial infarction. Using the $\chi^{2}$ test (Hoel, 1947), it was found that there was no statistical significance in the effect of sun spot activity on total deaths from all causes.

\section{Discussion}

There are many reports that suggest that certain meteorological phenomena are associated with an increased incidence of acute myocardial infarction. This has been variously ascribed to: (a) cold weather (Halse and Quennet, 1948; Wolff and White, 1926; Mullins, 1936; Master and Jaffe, 1952; Wood and Hedley, 1935; Bean and Mills, 1938; Mintz and Katz, 1947; Afanasieva, 1957); (b) sudden changes in weather (Petersen, 1947a; Cowdry, 1933; Newton, 1951; De Takats et al., 1940; Teng and Heyer, 1955; Afanasieva, 1957; Moriyama and Herrington, 1938), and (c) barometric pressure (Stocks, 1925). Most of these reports are about equally divided between cold weather and sudden changes in weather. Some of the proponents of the cold weather theory believe that the increased respiratory infections (Bean and Mills, 1938; Hoxie, 1940; Moriyama and Herrington, 1938) and the increase in body metabolism (Mills, 1939; Bean and Mills, 1938) associated with the winter months contribute to the attacks. Sudden changes in weather are thought to overtax the vasomotor mechanism, producing an acute myocardial infarction (Petersen, 1947b).

In the present study the months, March, April, and May were designated the spring months; while December, January, and February were the winter months. This division was employed to facilitate the comparison with a composite and similar clinical study (Heyer et al., 1953) which reported the highest incidence of acute myocardial infarction during the winter months and during the month of December. In an autopsy study (Bean, 1937) done in Boston the highest incidence of acute myocardial infarction was in the spring months and in the month of April. There are other reports (Smith et al., 1951; Jacobs, 1951) which do not reveal any striking, seasonal and monthly incidences of acute myocardial infarction in comparable areas of the United States. In terms of random numbers, the seven-year study of acute myocardial infarction in Stamford, Connecticut revealed the highest incidence during the spring months and during the month of April. However, these random incidences were not statistically significant.

Although the meteorological phenomena observed in the present study had no effect on the incidence of acute myocardial infarction it does not preclude the possible effect on its incidence by some, as yet uninvestigated, meteorological factor.

\section{SUMMARY}

In a seven-year study in Stamford, Connecticut the random incidence of acute myocardial infarction was highest during the spring months (March, April, and May) and in the month of April. However, these random incidences were not statistically significant. 
The meteorological phenomena of temperature, precipitation, barometric pressure, sun spots, and cosmic rays did not have any effect on the incidence of acute myocardial infarction.

The authors gratefully acknowledge the invaluable assistance of Drs. Charles H. Smiley and Nibondah Maigate, Brown University, Providence, Rhode Island; the suggestions of Dr. Alan V. Goodyer, Yale University School of Medicine, New Haven, Connecticut; the technical assistance of Miss Adele Glogan and Mrs. Alene D. Gregory; and the co-operation of the Records Department of The Stamford Hospital, The St. Joseph's Hospital, and the Town Clerk's Office, Stamford, Connecticut.

\section{REFERENCES}

Afanasieva, V. D. (1957). The relationship between myocardial infarction and meteorological factors. Sovetsk. Med., 21, No. 5, p. 115.

Bean, W. B. (1937). Infarction of the heart. A morphological and clinical appraisal of 300 cases. Part I. Predisposing and precipitating conditions. Amer. Heart J., 14, 684.

_, and Mills, C. A. (1938). Coronary occlusion, heart failure, and environmental temperatures. Amer. Heart J., 16, 701 .

Billings, F. T., Jr., Kalstone, B. M., Spencer, J. L., Ball, C. O. T., and Meneely, G. R. (1949). Prognosis of acute myocardial infarction. Amer. J. Med., 7, 356.

Brown, H. R., Jr., and Pearson, R. (1948). Seasonal variations in heart and coronary disease as related to various environmental factors. Amer. Heart J., 35, 763.

Bundesen, H. N., and Falk, I. S. (1926). Low temperature, high barometer and sudden death. J. Amer. med. Ass., 87, 1987.

Chambers, W. N. (1946). Acute myocardial infarction. A study of 100 consecutive cases. New Engl. J. Med., 235, 347.

Cowdry, E. V. (1933). Arteriosclerosis: A Survey of the Problem, p. 21. Macmillan, New York.

De Takats. G., Mayne, A., and Petersen, W. F. (1940). The meteorologic factor in pulmonary embolism. Surgery, $7,819$.

Fabricant, N. D. (1939). The climatic factor in precipitating acute tonsillitis in children. J. Pediat., 15, 697.

(1940). Weather and the climate. Amer. J. med. Sci., 200, 835.

Friedberg, C. K. (1949). Diseases of the Heart, p. 405. Saunders, Philadelphia.

Gould, S. E. (1953). Pathology of the Heart, 1st ed., pp. 567, 579, 615. Thomas, Springfield, Illinois.

Halse, T., Jr., and Quennet, G. (1948). Klimatsche Einflüsse in der Thrombogenese. Dtsch. med. Wschr., 73, 125.

Hayes, D. M. (1961). The seasonal incidence of acute leukemia. Cancer (Philad.), 14, 1301.

Heyer, H. E., Teng, H. C., and Barris, W. (1953). The increased frequency of acute myocardial infarction during summer months in a warm climate: a study of 1,386 cases from Dallas, Texas. Amer. Heart J., 45, 741.

Hoel, P.G. (1947). Introduction to Mathematical Statistics, p. 186. Wiley, New York.

Hoxie, H. J. (1940). Seasonal incidence of coronary occlusion in a mild climate (Los Angeles); a study based upon autopsy material. Amer. Heart $J ., 19,475$.

Huntington, E. (1938). Season of Birth, p. 6. Wiley, New York.

Jacobs, T. P. (1951). The initial attack of acute myocardial infarction. Ann. intern. Med., 34, 114.

Jones, W. H. S. (1948). Hippocrates, Vol. I, pp. 73, 115. Harvard University Press, Cambridge, Massachusetts.

Master, A. M., and Jaffe, H. L. (1952). Factors in the onset of coronary occlusion and coronary insufficiency. $J$. Amer. med. Ass., 148, 794.

Mills, C. A. (1939). Medical Climatology: Climatic and Weather Influences in Health and Disease, p. 262. Thomas, Springfield, Illinois. (1942). Climate Makes the Man, p. 225. Harper, New York.

Mintz, S. S., and Katz, L. N. (1947). Recent myocardial infarction; an analysis of 572 cases. Arch. intern. Med., 80, 205.

Mitchell, S. Weir (1877). The relations of pain to weather, being a study of the natural history of a case of traumatic neuralgia. Amer. J. med. Sci., 73, 305.

Moriyama, I. M., and Herrington, L. P. (1938). The relation of diseases of the cardiovascular and renal systems to climatic and socio-economic factors. Amer. J. Hyg., 28, 423.

Mullins, W. L. (1936). Age incidence and mortality in coronary occlusion: a review of 400 cases. Penn. med. J., $39,322$.

Newton, M. (1951). Relationship of weather to post-operative phlebothrombosis. Amer. J. Surg., 81, 607.

Petersen, W. F. (1947a). Man. Weather. Sun, pp. 316, 329. Thomas, Springfield, Illinois. (1947b). Organic variability in heart disease. Postgrad. Med., 1, 36.

Rentschler, E. B., Vanzant, F. R., and Rowntree, L. G. (1929). Arthritic pain in relation to changes in weather. J. Amer. med. Ass., 92, 1995. 
Schnur, S. (1956). Mortality rates in acute myocardial infarction. IV. The seasonal variation in morbidity and mortality. Ann. intern. Med., 44, 476.

Smiley, C. H. (1960). The antiquity and precision of Mayan astronomy. R.A.S.C. J., 54, 221.

Smith, F. J., Keyes, J. W., and Denham, R. M. (1951). Myocardial infarction: A study of the acute phase in 920 patients. Amer. J. med. Sci., 221, 508.

Stocks. P. (1925). High barometer and sudden deaths. Brit. med. J., 2, 1188.

Teng, H. C., and Heyer, H. E. (1955). The relationship between sudden changes in weather and the occurrence of acute myocardial infarction. Amer. Heart J., 49, 9.

Thomas, C. B., Holljes, H. W. D., and Eisenberg, F. F. (1961). Observations on seasonal variations in total serum cholesterol levels among healthy young prisoners. Ann. intern. Med., 54, 413.

Wolff, L., and White, P. D. (1926). Acute coronary occlusion. Boston med. surg. J., $195,13$.

Wood, F. C., and Hedley, O. F. (1935). The seasonal incidence of acute coronary occlusion in Philadelphia. Med. Clin. N. Amer., 19, 151. 